\title{
Low-density koala (Phascolarctos cinereus) populations in the mulgalands of south-west Queensland. IV. Abundance and conservation status
}

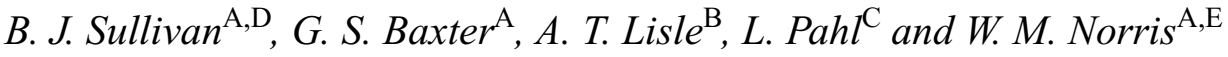

 \\ Gatton, Qld 4343, Australia. \\ ${ }^{\mathrm{B}}$ School of Agronomy and Horticulture, The University of Queensland, Gatton, \\ Qld 4343, Australia. \\ ${ }^{\mathrm{C}}$ Agency for Food and Fibre Sciences, Queensland Department of Primary Industries, \\ PO Box 102, Toowoomba, Qld 4350, Australia. \\ DPresent address: South-west Atlantic Seabirds at Sea Team, Falklands Conservation, \\ Jetty Centre, Stanley, Falkland Islands. \\ EPresent address: Fisheries Resource Management, Department of Primary Industries, \\ GPO Box 46, Brisbane, Qld 4001, Australia.
}

\begin{abstract}
Urban encroachment on dense, coastal koala populations has ensured that their management has received increasing government and public attention. The recently developed National Koala Conservation Strategy calls for maintenance of viable populations in the wild. Yet the success of this, and other, conservation initiatives is hampered by lack of reliable and generally accepted national and regional population estimates. In this paper we address this problem in a potentially large, but poorly studied, regional population in the State that is likely to have the largest wild populations. We draw on findings from previous reports in this series and apply the faecal standing-crop method (FSCM) to derive a regional estimate of more than 59000 individuals. Validation trials in riverine communities showed that estimates of animal density obtained from the FSCM and direct observation were in close agreement. Bootstrapping and Monte Carlo simulations were used to obtain variance estimates for our population estimates in different vegetation associations across the region. The most favoured habitat was riverine vegetation, which covered only $0.9 \%$ of the region but supported $45 \%$ of the koalas. We also estimated that between 1969 and $1995 \sim 30 \%$ of the native vegetation associations that are considered as potential koala habitat were cleared, leading to a decline of perhaps $10 \%$ in koala numbers. Management of this large regional population has significant implications for the national conservation of the species: the continued viability of this population is critically dependent on the retention and management of riverine and residual vegetation communities, and future vegetation-management guidelines should be cognisant of the potential impacts of clearing even small areas of critical habitat. We also highlight eight management implications.
\end{abstract}

\section{Introduction}

In the latter part of the 20th Century the koala (Phascolarctos cinereus) has become a conservation icon and national symbol. Yet since European settlement of Australia management of the species has been mostly ad hoc, often incidental to land management, and based on few data about population size.

Despite the lack of data there have been numerous public and institutional expressions of concern for the future of the species. In 1992 the International Union for the Conservation of Nature (IUCN) Scientific Australian Marsupial and Monotreme Specialist Group classified the national conservation status of the koala as 'Potentially Vulnerable'. The draft Action Plan for Australian Monotremes and Marsupials (Maxwell et al. 1996) assessed its conservation status as lower risk ('near threatened') using the 1994 IUCN criteria. It estimated that there were more than 50000 koalas in Australia, but gave no indication of an upper limit. However, the koala is not listed by the Australian Federal Endangered Species Protection Act 1992. Recently the non-government organisation (NGO), Australians for Animals, successfully lobbied policy makers in the United 
States of America and the koala is now listed as a threatened species under the United States of America Department of the Interior, Fish and Wildlife Service, Endangered Species Act.

It is generally acknowledged that the koala's former geographic range has contracted by more than $50 \%$ since European settlement (Phillips 1990; Maxwell et al. 1996). However, organisations have vastly different views on national and statewide abundance and conservation status. For example, the NGO Australian Koala Foundation estimates that the national population is 45000-80000 (25-50000 in Queensland and 10-15000 in both New South Wales and Victoria (Sharp 1995). This contrasts sharply with other estimates, for example 170000 in Queensland alone (G. Gordon, Queensland National Parks and Wildlife Service, personal communication), up to 10000 in New South Wales (Lunney et al. 2000), and 75000-130000 for the Strathbogie Plateau in Victoria (Melzer et al. 2000). The uncertainty of population estimates is further illustrated by Phillips (2000), who estimated koala abundance for the Strathbogie Ranges by modelling population growth from a known history of introductions and an expected rate of increase. These models suggested a best-case scenario of $<30000$ koalas, without accounting for assumptions of habitat homogeneity, non-limiting food resources, mortality and stochastic events.

Around $40 \%$ of the natural distribution of the koala occurs in tropical, subhumid and semi-arid regions of the continent (Phillips 1990), and almost all of that is in Queensland. However, little is known of the abundance of koala populations in these areas (Melzer and Lamb 1994). Their current distribution in Queensland has largely been derived from questionnaire surveys, and many local koala populations in northern, central and western Queensland may remain unreported or unknown (Patterson 1996).

The most significant threat to the long-term conservation of koalas is habitat loss, although drought, wildfire, disease, predation and vehicle strikes are also serious threats (Melzer et al. 2000). Despite these threats and the level of uncertainty regarding the abundance of koalas, it has been suggested that conservation intervention should be taken now, since there is clear evidence of decline in some populations while the existence of other robust populations offers the possibility of a variety of creative solutions (Sherwin et al. 2000). The primary aim of the National Koala Conservation Strategy is to conserve koalas by retaining viable populations in the wild throughout their natural range (ANZECC 1998). However, the lack of reliable, or even generally agreed, national estimates of abundance for this species presents clear difficulties (Cork et al. 2000). Until a nationally recognised standard (with regionally specific and compatible survey methodologies) is adopted to derive an acceptably precise estimate of koala abundance across all states, ad hoc estimates and best guesses will continue to cause controversy and retard practical koala conservation initiatives.
The first paper in this series (Sullivan et al. 2002) detailed the development and statistical validation of our pellet-sampling protocol and the second (Sullivan et al. $2003 a$ ), the diet and distribution of koalas within the study area. The third paper in the series (Sullivan et al. 2003b) applied GIS technology, a relative habitat-utilisation index and logistic regression modelling based on the presence/absence of pellets to identify broadscale habitat utilisation, and discussed the biotic factors that appear to determine these patterns.

In this, the final paper in the series, we report regional density estimates, and describe the application of a geographic information system (GIS) to convert broadscale survey density data to regional estimates of koala abundance, derive bootstrapped variance estimates for those abundances and discuss the conservation significance of our findings. Given that Queensland is likely to have the largest koala populations, determining their abundance in regional Queensland is a critical component to the success of the National Koala Conservation Strategy and will help to place the management of the species on a more informed footing.

\section{Methods}

Study area

This study was conducted in the Queensland portion of the mulgalands biogeographic region (Fig. 1), which covers more than $190000 \mathrm{~km}^{2}$ and is described in detail by various authors (e.g. Neldner 1984; Thackway and Cresswell 1995; Wilson 1999).

\section{Application of the faecal standing-crop method}

Koala density estimates are derived from data collected from a multi-scaled, stratified survey of the mulgalands. The sampling rationale and location of the sampling sites is provided in detail in Sullivan et al. $(2003 a, 2003 b)$.

We calculated koala density using the faecal standing-crop method (FSCM, as used by Johnson and Jarman 1987; Latham et al. 1996).

$$
\text { Koala density }=P / d a \text {, }
$$

where $P=$ pellet abundance, $d=$ daily pellet production and $a=$ maximum pellet age. The methods used to estimate $P$ and $a$ are described in detail in Sullivan et al. (2002).

By adapting a method used to capture koalas (Hasegawa and Carrick 1995) we estimated daily pellet production rates $(d)$ in 8 free-ranging koalas ( 3 males and 5 females) of different ages located in a range of habitats in different seasons. A 1.5-m-high sheet of metal was placed in a circle $\sim 2 \mathrm{~m}$ from the base of a tree in which a koala was found, forming a barrier that the koala could not climb. In this way an animal was confined to a single tree for $24 \mathrm{~h}$. Black plastic sheeting was placed under the entire canopy to separate any previously deposited pellets from those deposited during the period of confinement, and to ensure that vegetation or litter did not hinder pellet collection.

Once estimated with $95 \%$ confidence limits, this parameter $(d$, Eqn 1) was applied to calculate density estimates for all sites, for the duration of the study. However, the age $(a)$ at which pellets reached the threshold between the 'new' and 'old' class varied depending on seasonal weather conditions and was applied to data collected at that time only (Sullivan et al. 2002). 
Table 1. Vegetation visibility class characteristics

\begin{tabular}{ccc}
\hline Visibility class & \% ground cover of litter/pebbles & $\begin{array}{c}\text { \% visibility of ground through } \\
\text { vegetative cover }\end{array}$ \\
\hline 1 & $<20$ light litter/pebbles & $>80$ \\
2 & 100 light litter/pebbles & $51-80$ \\
3 & 100 light to dense litter & $21-50$ \\
4 & 100 dense litter & up to 20 \\
5 & 100 extremely dense litter & 0 \\
\hline
\end{tabular}

The density of koala faecal pellets was estimated from quadrat counts under trees (see Sullivan et al. 2002 for details). Ground vegetation and cover greatly affected the time taken to search any quadrat, and had the potential to bias estimates of pellet density if pellets were missed in quadrats placed in different vegetation cover. To minimise this potential source of bias we recognised five vegetation visibility classes (Table 1), and developed correction factors and standard search times for quadrats in each one.

We quantified the number of pellets obscured in each visibility class by conducting a thorough search under litter and/or vegetative growth present in the quadrat, as would be conducted under normal field conditions (standard count). All vegetation and litter were then removed from the quadrat, using hedge trimmers when necessary, and all pellets in the quadrat were counted. Linear regression was used to compare several models for predicting the actual number of pellets from the standard count in each visibility class.

To calculate site-specific pellet abundance, the data from each individual sampling quadrat (Sullivan et al. 2002) were adjusted to account for differential pellet detectability due to variable vegetation ground cover. For estimates in residual, floodplain and plains landforms, the adjusted densities were then multiplied by the estimated canopy area of the tree under which they were found. For riverine communities, where trees often had large and asymmetrical canopies, the pellet density was calculated by multiplying the corrected density in quadrats in each quarter of the tree canopy by the area of that quarter, then summing the four estimates for each tree (see Sullivan et al. 2002). We then calculated $P$ for each site by summing adjusted data from each tree.

We used Equation 1 to estimate a range of koala densities for each site. Maximum density was calculated using minimum figures for daily pellet production and pellet age, and the minimum density used the respective maximum figures.

\section{Habitat loss (aerial photographic interpretation)}

Since the only available GIS coverage of the mulgalands was based on 1969 aerial photography, it was necessary to estimate the area of each habitat unit that had been cleared since that time. We did this by aerial photograph interpretation (API). Most of the most recent photographs available were taken since 1994 . However, for a few very small areas the most recent photos were taken in the early 1990s.

In the last thirty years considerable habitat clearance and fragmentation has taken place across the entire region. For example, between 1991 and 1995, $633 \mathrm{~km}^{2}$ of vegetation per year was cleared in the mulgalands biogeographic region, which represents $0.34 \%$ of the total area per year (SLATS 1999a).

At 207 randomly selected API sites a $100-\mathrm{cm}^{2}$ grid consisting of one hundred $10-\mathrm{mm}^{2}$ cells was placed over the photograph, with the selected site located in the centre of the grid. The vegetation in each cell was categorised as being either cleared or uncleared. If a selected site did not occur within one of our defined habitat units, another site was randomly selected. The same process was followed to select sites within each habitat unit in approximate proportion to their relative area Finally, we used a maximum-likelihood estimator, weighted according to sample size, to estimate the 'current' area of each habitat unit within each sampling zone (SZ):

$$
\sum\left(x_{\mathrm{i}}-q y_{\mathrm{i}}\right)^{2} /(n-1)\left(\sum y\right)^{2},
$$

where $x_{I}=$ units in original state, $y_{i}=$ units assessed and $q=x / y$.

These adjusted figures were then used to extrapolate koala densities across the study area.

\section{Density extrapolation across the region}

All density data were extrapolated using the API-adjusted area estimates for each of the 10 primary sampling units (habitat units). Each habitat unit was formed by combining similar vegetation associations on the basis of their floristic and edaphic composition (see Sullivan et al. 2003a). Koala abundance across the study area was estimated using a data interpolator to assign values to points for which there were no data. Given the high degree of variation in density estimates and the broadscale nature of the survey, we chose to apply an inverse distance weighting (IDW) interpolator because it assumes that the influence of an observation is inversely related to its distance from the point to be estimated (Watson and Philip 1985).

The precision of any weighted average interpolation exercise depends on the function used, or its parameters, and on the size of the domain or area from which sample points are chosen (Hodgson 1992). Our multiscaled stratification process consisted of dividing the study area into three rainfall zones (RFZ) based on annual median rainfall and overlaying three latitudinal zones to form nine SZs (Fig. 1) (see Sullivan et al. 2003a, $2003 b$ for details). We then chose a global approximation interpolator (Chou 1997) to create separate IDW surfaces for each habitat unit in the six sampling zones from which 'new' pellets were recovered.

The distance parameter of IDW models has historically been 1.0 or 2.0 (Hodgson 1992). We chose a weighting of 2.0 to assign a greater weight to nearby points to capture local-scale density variations.

We generated a separate IDW surface for minimum-, mean- and maximum-density estimates. Density categories for each IDW surface were determined by inspecting a histogram of the estimated densities for each habitat unit in each SZ. Habitat units with a regular distribution of densities were assigned equal density categories and those with an irregular distribution were assigned density categories by Jenk's optimisation formula, which generates classes based on natural breaks in the data (ESRI 1996). For habitat units with only one site with new pellets per SZ we generated a surface for a $50-\mathrm{km}$ radius around the point.

\section{Variance estimates}

We used the method outlined by Efron and Tibshirani (1986) to generate 500 bootstrap estimates of pellet abundance for each of the 149 sampling sites, which generated a site-specific measure of the potential range of pellet numbers present. Next, we converted these data into koala densities (via the FSCM) and conducted a Monte Carlo simulation to generate a variance estimate of koala abundance. This was achieved by randomly selecting 100 bootstrap estimates for each site and generating density estimates for each. Then 50 randomly selected 


Table 2. Pellets collected from confined koalas to determine mean
defaecation rates

delineated using aerial photography and subsequently ground-truthed and marked using flagging tape.

Initially, new pellets were sampled as described above at both sites in one 1-ha transect $(1 \mathrm{~km} \times 10 \mathrm{~m})$ positioned along the river bed and another placed perpendicular to the river in the surrounding plains habitat. These data were extrapolated over their respective habitat areas (i.e. riverine and plains) to estimate the number of pellets present. Then the FSCM was used to estimate the number of koalas within the site.

To conduct the direct counts 7 people were positioned abreast to search every tree within the clearly defined riverine habitat at both sites. The riverine community at Nebine Creek (Site 1) was, on average, 30 $\mathrm{m}$ wide and at Mungallala Creek (Site 2) it was $40 \mathrm{~m}$ wide, so it was possible to position people such that every tree was searched by a minimum of 2 people (often 3 or 4 ) observing from different angles. The plains habitat on both sides of the creek was searched in the same way. At Site 1 it was possible to spread 7 people at $30-\mathrm{m}$ intervals to cover the $250 \mathrm{~m}$ on either side of the creek in one pass. However, at Site 2 the density of trees in the plains communities necessitated the spread of 7 people over $125 \mathrm{~m}$, so 2 passes were made on each side of the creek.

estimates were used to run a Monte Carlo simulation to generate 50 koala abundance estimates for each habitat unit in each SZ. We considered 50 simulations for each (per SZ) to be adequate to determine the variance of the abundance estimate as samples as small as 25 can give reasonable standard error estimates (Efron and Tibshirani 1986). However, it is desirable to have a much larger sample size to generate confidence intervals (Efron and Tibshirani 1986). Because we manually inspected the distribution of estimated densities for each coverage to decide on the method used to generate density categories, the computation time to generate so many coverages using Arcview (Spatial Analyst) was enormous. Therefore it was not feasible to generate more than 50 coverages for each habitat unit in each SZ. The Monte Carlo simulation was not run for 6 habitat units with an abundance estimate of $<100$ koalas.

We calculated both the standard error of the mean estimate and $95 \%$ confidence intervals of the estimate. Confidence intervals for the mean Monte Carlo simulation were estimated by multiplying the estimated standard error by the appropriate tabulated $t$.

\section{Field validation of sampling protocol}

In addition to the statistical validation of the pellet-sampling protocol (see Sullivan et al. 2002), the accuracy of koala densities derived from the protocol were assessed in the field by comparing them with density estimates derived from direct animal counts obtained on belt transects.

Our data were collected at two sites in the eastern portion of the study area (Fig. 1). Both sites consisted of a linear riverine community dominated by river red gums surrounded by plains communities dominated by scattered poplar box (Eucalyptus populnea) trees and Eremophila mitchelii shrubs. At both sites a 150-ha quadrat, $3 \mathrm{~km}$ long and $500 \mathrm{~m}$ wide $(250 \mathrm{~m}$ either side of the riverine habitat), was

\section{Results}

\section{Application of the FSCM}

The mean daily pellet production for free-ranging koalas was $150.75 \pm 12.55$ (95\% CI) (Table 2).

We fitted a parallel-lines model to predict the actual pellet count from the standard count for quadrats in four of the five visibility classes, since allowing the slope to vary between classes did not significantly improve the model. Based on this model, a correction factor was applied to the number of pellets recorded in each quadrat in each visibility class (Table 3). No correction was necessary for Visibility Class 1 (Table 3).

\section{Habitat loss (aerial photographic interpretation)}

In this study no new pellets were found anywhere in RFZ I (which contained SZs 1, 4 and 7), so habitat loss was not measured there. The total estimated percentage of cleared land for each SZ follows a general increasing trend from RFZ II to RFZ III, with a marked peak in SZ 6 (Fig. 2). We estimate that over the last 30 years in RFZs II and III there has been a $32 \%$ reduction in the vegetation associations that comprise our habitat units. This reduction has been markedly higher in RFZ III (Table 4). 
Table 3. Correction factors applied to each visibility class

\begin{tabular}{ccc}
\hline Visibility class & Sample size & Correction factor (s.e.) \\
\hline 1 & 1380 & $0.00+1 \times$ observed $^{\mathrm{A}}$ \\
2 & 2193 & $-0.0194+1.090 \times$ observed $(0.2490)$ \\
3 & 771 & $0.3969+1.090 \times$ observed $(0.2958)$ \\
4 & 97 & $4.276+1.090 \times$ observed $(0.3205)$ \\
5 & 34 & $1.934+1.090 \times$ observed $(0.0197)$
\end{tabular}

ANo correction necessary.

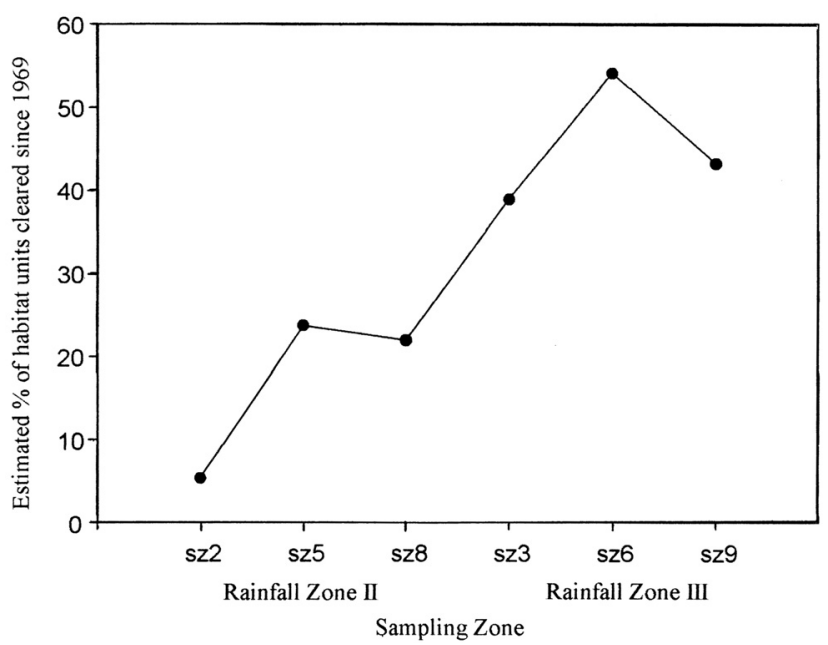

Fig. 2. Estimated percentage of habitat units cleared since 1969 (based on aerial photography interpretation) in each sampling zone (SZ).

The estimated percentage of cleared vegetation varied greatly for the same habitat units in different SZs. The maximum extent of clearing, relative to the 1969 base, was $\sim 80 \%$ in Habitat Units 5 and 7 in SZ 3, Habitat Units 4 and 7 in SZ 6 and Habitat Unit 8 in SZ 9, all of which are located in RFZ III. In contrast, the highest estimated extent for RFZ II was $\sim 30 \%$ in Habitat Units 3 and 6 in SZ 5.

\section{Koala density estimates}

Estimated densities across the study area for all sites with 'new' pellets ranged from 0.0007 to $2.513 \mathrm{ha}^{-1}$. The highest densities were typically recorded in Habitat Unit 1 in SZs 3, 6 and 9 (RFZ III), and the next highest in Habitat Unit 9 in SZs 3 and 6. The lowest densities were recorded in Habitat Units 1 and 6 in SZs 8 and 5.

\section{Koala abundance estimates}

Using data collected at 149 sites and the adjusted habitat area figures we derived a population estimate of 59500. The bootstrap Monte Carlo simulation was that koala abundance in the study area ranges from $44900-81100 \pm(95 \% \mathrm{CI})$ with a mean estimate of $63000 \pm 1280$ (s.e.).

Abundance estimates varied greatly between habitat units (the dominant floristic components of the 10 habitat units is
Table 4. Estimated reduction of vegetation associations that comprise habitat units in RFZs II and III

\begin{tabular}{lcc}
\hline & RFZ II & RFZ III \\
\hline Area in 1969 & 5566557 & 5067365 \\
Area in 1995 & 4565419 & 2576914 \\
Estimated reduction & $18 \%$ & $49.1 \%$ \\
\hline
\end{tabular}

detailed in Sullivan et al. 2003a) and SZs (Table 5). As no new pellets were collected in RFZ 1 (Sullivan et al. 2003a), no koala-density estimates were possible for any habitat units in SZ 1, 4 and 7. Habitat Unit 1 in SZ 6 had considerably more koalas than any other habitat unit. The next highest abundance estimate was obtained in Habitat Unit 10 of SZ 2. At the scale of RFZ, SZ and habitat unit, riverine communities (Habitat Unit 1) are the single habitat unit with the highest estimated number of koalas, and SZ 6 has considerably more koalas than all other SZs combined. At the RFZ scale, RFZ III has more than double the estimated number of koalas than RFZ II (Table 6).

However, the combined abundance of koalas in residual habitat units (Habitat Units 9 and 10) suggests that residual landforms had slightly more koalas than riverine landforms. Residual and riverine communities combined accounted for $\sim 94 \%$ of the total abundance estimate (Table 7).

Assuming that the direct loss of habitat was the only factor causing a reduction in koala numbers, on the basis of our density estimates $\sim 66300$ koalas would have been found in the region in 1969 (Table 8). That represents a possible reduction of $\sim 10 \%$ in the last 30 years.

\section{Field validation of sampling protocol}

No pellets were recovered in the plains communities surrounding the riverine communities at either site, so the pellet-based density estimates were extrapolated only over the homogenous riverine habitat. For both validation sites the upper density estimate of the pellet-sampling protocol under-estimated $<20 \%$ compared with the direct koala count densities (Table 9).

In western Queensland, riverine communities provide optimum koala habitat (Gordon et al. 1988, 1990; Witt and Pahl 1995; Munks et al. 1996). We therefore concentrated our field validation effort in riverine communities, where the precision of the protocol was deemed to be most critical.

\section{Discussion}

In recent times pellet-sampling methods are frequently used to survey koala populations (e.g. Hasegawa 1995; Munks et al. 1996; Pahl 1996; Lunney et al. 2000; Phillips et al. 2000). Barnes (1996) noted that for elephants, direct count methods have been validated and fine-tuned, whereas dung counts are still evolving. A similar situation occurs in Australia where pellet-count methods, particularly those for arboreal mammals, are relatively untested compared with more 
Table 5. Estimated abundance of koalas in each habitat unit and sampling zone

\begin{tabular}{ccccc}
\hline Sampling zone & Habitat unit & \multicolumn{3}{c}{ Abundance estimate on 1995 vegetation areas } \\
Minimum & Mean & Maximum \\
\hline 2 & 10 & 10323 & 13007 & 16097 \\
3 & 1 & 526 & 815 & 1137 \\
& 10 & 2245 & 2766 & 2814 \\
& 9 & 1558 & 2521 & 3573 \\
& 7 & 126 & 160 & 188 \\
& 3 & 8 & 13 & 16 \\
5 & 2 & 27 & 34 & 54 \\
& 1 & 1026 & 1329 & 1777 \\
& 10 & 1271 & 2114 & 2588 \\
& 9 & 51 & 69 & 87 \\
6 & 5 & 23 & 23 & 23 \\
& 3 & 706 & 806 & 1064 \\
& 1 & 1597 & 1621 & 1888 \\
& 10 & 1133 & 1375 & 1559 \\
& 9 & 5340 & 7408 & 9787 \\
& 8 & 61 & 99 & 130 \\
& 5 & 612 & 1236 & 2246 \\
& 5 & 570 & 648 & 796 \\
& 2 & 16281 & 21492 & 26739 \\
& 1 & 33 & 42 & 48 \\
& 1 & 227 & 296 & 355 \\
& 7 & 849 & 1681 & 2671 \\
& 1 & & &
\end{tabular}

traditional direct count methods. While some studies have identified limitations to counting accumulations of koala pellets to determine tree-species preferences (Hasegawa 1995; Pahl 1996), these studies were based on arbitrarily sampling an unknown proportion of pellets beneath a tree, or using presence/absence of pellets around the base of trees to derive a habitat-utilisation index (Phillips et al. 2000). Ours is the first method to validate the use of pellet searches around the base of trees (basal pellet searches: Sullivan et al. 2002) as a means of identifying trees with and without pellets, and to develop correction factors to account for varying levels of pellet detection. These data were critical in estimating both pellet and koala abundance. We also provide a measure of variance of this estimate, which has previously been a deficiency in regional koala-abundance estimates.

\section{Faecal standing-crop method}

Of the three parameters required for the FSCM (pellet abundance, maximum pellet age and daily pellet production), the last was the final variable to be quantified (for details of the other two see Sullivan et al. 2002). Our estimate of daily pellet production of $150.75 \pm 12.55(95 \%$ CI) concurs well with the only other published estimate of mean daily pellet production of $174 \pm 29$ pellets day $^{-1}$ for captive koalas fed Eucalyptus browse ad libitum (Ellis et al. 1998), especially considering the potential differences in pellet production from free-ranging to captive koalas. However, the digestion processes of koalas are likely to be regular rather than episodic, because the koala has evolved to the physiological limits possible for a mammal to survive on a sclerophyllous diet that is low in nutrients and protein and high in potentially toxic constituents (Cork and Sanson 1990). Thus pellet production is likely to be fairly uniform across habitats and even geographical regions.

\section{Land-management practices}

\section{Habitat clearance}

The vastly different estimated percentage of habitat units cleared in RFZs II and III (Fig. 2) are a consequence of the different land-management practices in the two regions. The greater level of clearing in the eastern portion of the study area (RFZ III, Fig. 1) is a reflection of the perceived level of economic return to graziers obtained by increased pasture cover in this region, and possibly the higher rates of regeneration (thickening) that have occurred in many vegetation associations. The critical importance of protecting habitat in RFZ III is emphasised by a range of indicators. The area has the most homogenous distribution of koalas in the mulgalands (Sullivan et al. 2003a), and koalas in the area potentially have the opportunity to access significantly more habitat units than koalas in the other two RFZs (Sullivan et al. 2003b), which would potentially increase resource access. RFZ III also has the highest densities of koalas, which translates to approximately twice the estimated koala abundance of RFZ II (Table 6).

The relative importance of residual and riverine habitats to koalas is clear from the estimated abundance of koalas in 
Table 6. Summary of koala abundance estimates at the RFZ, SZ and habitat unit levels $\mathrm{zr}=$ zero new pellet records

\begin{tabular}{|c|c|c|c|}
\hline & \multicolumn{3}{|c|}{ Abundance estimate } \\
\hline & Minimum & Mean & Maximum \\
\hline \multicolumn{4}{|c|}{ Rainfall zone } \\
\hline 1 & $\mathrm{zr}$ & $\mathrm{zr}$ & $\mathrm{zr}$ \\
\hline 2 & 14530 & 18490 & 22930 \\
\hline 3 & 30060 & 41050 & 52700 \\
\hline \multicolumn{4}{|c|}{ Sample zone } \\
\hline 1 & $\mathrm{zr}$ & $\mathrm{zr}$ & $\mathrm{zr}$ \\
\hline 2 & 10849 & 13822 & 17234 \\
\hline 3 & 4990 & 6823 & 8422 \\
\hline 4 & $\mathrm{zr}$ & $\mathrm{zr}$ & $\mathrm{zr}$ \\
\hline 5 & 3648 & 4633 & 5650 \\
\hline 6 & 23997 & 32258 & 41257 \\
\hline 7 & $\mathrm{zr}$ & $\mathrm{zr}$ & $\mathrm{zr}$ \\
\hline 8 & 33 & 42 & 48 \\
\hline 9 & 1076 & 1977 & 3026 \\
\hline \multicolumn{4}{|c|}{ Habitat unit } \\
\hline 1 & 20312 & 26980 & 34260 \\
\hline 2 & 597 & 682 & 850 \\
\hline 3 & 714 & 819 & 1080 \\
\hline 4 & $\mathrm{zr}$ & $\mathrm{zr}$ & $\mathrm{zr}$ \\
\hline 5 & 635 & 1259 & 2269 \\
\hline 6 & $\mathrm{zr}$ & $\mathrm{zr}$ & $\mathrm{zr}$ \\
\hline 7 & 353 & 456 & 543 \\
\hline 8 & 61 & 99 & 130 \\
\hline 9 & 6949 & 9998 & 13447 \\
\hline 10 & 15298 & 18769 & 22358 \\
\hline
\end{tabular}

each landform class (Table 7). The relative habitat-utilisation index (Hi) presented in Sullivan et al. (2003b) also highlights the importance of these communities, and suggests a trend of decreasing relative importance of residual communities associated with an increasing relative importance of riverine communities in a southerly direction (and vice versa) in RFZ II and III. Riverine communities comprise only 5.6\%, and residual habitat units (Habitat Units 9 and 10) 19\% of the total area of habitat units in RFZs II and III. We estimate that if $10 \%$ of the riverine communities in RFZ III alone were cleared it could reduce koala abundance in the study area by $\sim 9 \%$, even though these communities comprise only $0.9 \%$ of the total study area (including all vegetation communities).

The likely reduction in koala numbers over the last 30 years that we postulate here (Table 8 ) seems low compared with the amount of land cleared; however, most land cleared was plains communities that typically either do not have resident koala populations (e.g. Acacia-dominated communities) or have extremely low-density koala populations. Estimates of broadscale clearing of eucalypt woodland may overestimate koala habitat loss because they include eucalyptus communities beyond the natural range of the koala (Melzer et al. 2000). However, in reality, the reduction in koala numbers due to habitat clearance may have been considerably higher because of the further fragmentation of habitat.

Critical thresholds in landscape connectivity illustrate that fragmentation is not a linear function of habitat loss. Above the threshold the primary consequence of habitat removal is a decrease in the area of available habitat, and below the threshold the landscape is effectively disconnected into isolated patches of habitat (With et al. 1997). This depends not only on the size of habitat patches and their degree of isolation (Dunning et al. 1992; Andren 1994), but also on the dispersal characteristics of the species utilising the patches (Fahrig and Paloheimo 1988). During this study many sightings of koalas and their signs (pellets and tree scratches) were made in isolated trees and traversing cleared land and grasslands. Landholders and clearing contractors reported similar sightings. We also heard several accounts from landholders/bulldozer drivers of koalas moving through vast tracts of Acacia plains communities with no Eucalyptus trees. This suggests that koalas move and/or disperse through both cleared and uncleared vegetation communities that are apparently unsuitable for resident populations.

\section{Protection of koala habitat}

The Statewide Landcover and Trees Study (SLATS) Reports (SLATS 1999a, 1999b, 2000) provide the most recent summary of broadscale vegetation clearing practices in Queensland. The Mulgalands biogeographic region was the second most heavily cleared area within Queensland, accounting for $22 \%$ of the total area cleared in Queensland between 1991 and 1995, 17\% between 1995 and 1997, and 20\% between 1997 and 1999. The SLATS 2000 report shows that the rate of vegetation clearing is greatest in the eastern higher-rainfall areas of the Mulgalands biogeographic region. For example, between 1997 and 1999 the annual rates of vegetation clearance were $384 \mathrm{~km}^{2}$ for the west Balonne

Table 7. Estimated abundance of koalas by landform class

\begin{tabular}{lcccc}
\hline $\begin{array}{l}\text { Landform class } \\
\text { (habitat units) }\end{array}$ & Minimum & Mean & Maximum & $\begin{array}{c}\text { \% of mean } \\
\text { estimate }\end{array}$ \\
\hline Riverine (1) & 20312 & 26980 & 34260 & 45.4 \\
Floodplain (2, 3) & 1311 & 1501 & 1930 & 2.5 \\
Plains (4-8) & 1049 & 1814 & 2942 & 3.0 \\
Residual (9, 10) & 21921 & 29260 & 36505 & 49.1 \\
Total & 44593 & 59555 & 77567 & \\
\hline
\end{tabular}


Table 8. Current and indicative 1969 koala abundance estimates

\begin{tabular}{lccc}
\hline Date & Minimum & Mean & Maximum \\
\hline Pre-'recent' clearing & 50300 & 66300 & 83000 \\
$1995 / 96$ & 44500 & 59500 & 75600 \\
Change (\%) & $-5800(11.5)$ & $-6800(10.3)$ & $-7400(8.9)$ \\
\hline
\end{tabular}

plains (SZ 9), $147 \mathrm{~km}^{2}$ for the eastern mulga plains (SZ 6), $11-40 \mathrm{~km}^{2}$ for the Nebine plains, Warrego River plains and west Warrego plains (all three in SZs 2, 5 and 8), and $0.2-7 \mathrm{~km}^{2}$ for the Paroo sand sheets and west Bulloo plains (SZs 1, 4 and 7).

The figures on vegetation clearance presented in this study and in the more recent SLATS reports are not the only statistics that should be considered when determining changes in the extent of koala habitat following a century or more of pastoral industry land use in the mulgalands. Significant areas of regrowth and woody plant thickening exist in the mulgalands, adding sizeable areas of woody vegetation to this biogeographic region. The vegetation of the mulgalands mapped by the SLATS reports consists of all perennial woody plants of all sizes that can be distinguished with Landsat TM imagery (woody vegetation with a foliage projective cover of $5 \%$ or greater), and includes remnant native vegetation, disturbed native vegetation and regrowth (SLATS 2000). One-third of the native vegetation cleared between 1997 and 1999 was regarded as regrowth, with the other two-thirds regarded as remnant vegetation (SLATS 2000). Remnant vegetation is defined in the Vegetation Management Act 1999 as vegetation with more than $50 \%$ of the undisturbed predominant canopy, $70 \%$ of the vegetation's undisturbed height, and composed of species characteristic of the vegetation's undisturbed predominant canopy. Consequently, remnant vegetation may also include regrowth that has occurred after a previous clearing event, and woody vegetation that is a result of shrub and tree thickening that has occurred over several decades. Witt and Beeton (1995) noted considerable thickening of woody plant cover in a mulgalands National Park in south-west Queensland. They found that the woody cover in a number of land systems increased from $2-10 \%$ in 1952 to $20-50 \%$ in 1992 . In particular, Witt and Beeton (1995) noted major increases in woody cover after 1969, corresponding with the 1969 aerial photography that was the basis of the GIS coverage used in this study to determine loss of koala habitat. Thus, changes in the extent of koala habitat since 1969 documented by aerial photo interpretation in this study and more recently by SLATS, only represent losses in habitat. Significant additions through regrowth and thickening have not been accounted for.

The management of the vegetation remaining in the mulgalands falls under the control of recent state legislation. In September 1997, 34 sets of Local Tree Clearing Guidelines for leasehold land in Queensland received Ministerial approval. The Broadscale Tree Clearing Policy was finalised and Part 6 of the Land Act 1994 was proclaimed in October 1997. The mulgalands has been covered by 9 sets of Local Tree Clearing Guidelines (St George-Dirranbandi, Eastern Warrego, Warrego Floodplain, Western Warrego, Far Western Mulga, Maranoa, Northern Uplands, Blackall, and Isisford-Barcoo). These are now being reviewed, and will soon be replaced by the Regional Vegetation Management Plan for the Mulga Lands Bioregion. Under this new plan riverine communities (Habitat Unit 1) throughout the mulgalands will be protected by varying buffer widths, depending on stream order. In general, buffer widths for both sides of rivers, creeks and gullies are $200 \mathrm{~m}, 100 \mathrm{~m}$ and $50 \mathrm{~m}$ respectively. Riverine vegetation communities and all other forms of riparian and wetland vegetation, hard mulga and residual land systems will all be completely protected under the new vegetation-management plan (P. Voller, personal communication). Consequently, the vegetation that is most important for koalas, accounting for $94 \%$ of the koala population in the mulgalands (Habitat Units 1, 9 and 10), will be retained under the new legislation.

\section{Impacts of grazing}

The degradation of semi-arid rangelands is a global phenomenon that has received increasing attention in recent years (Walker and Steffen 1993). Evidence of such degradation includes a change in species dominance from palatable perennial grasses to woody shrubs and a reduction in landscape uniformity as native pastures become increasingly interspersed with scalded areas, woody weed infestation and erosion (Passmore and Brown 1992). Land-management practices in the mulgalands associated with grazing of introduced and native herbivores have caused a change in species dominance from palatable perennial grasses to woody shrubs and trees in some areas,

Table 9. Koala abundance and density $\left(\mathrm{koalas} \mathrm{ha}^{-1}\right)$ estimates from direct counts and pellets counts All koalas were recorded in riverine habitat. Minimum and maximum pellet age were measured in days. For the pellet protocol range estimates, the maximum is calculated using minimum figures for daily pellet production and pellet age, and minimum uses the respective maximum figures

\begin{tabular}{lcccccc}
\hline Site & Area & \multicolumn{2}{c}{ Direct visual counts } & Pellet age & \multicolumn{2}{c}{ Pellet protocol range estimates } \\
& (ha) & Numbers & Density & & Numbers & Density \\
\hline Nebine Creek & 9.3 & 3 & 0.32 & $17-19$ & $2.13-2.82$ & $0.23-0.30$ \\
Mungallala Creek & 13.2 & 6 & 0.45 & $16-18$ & $3.63-4.82$ & $0.27-0.36$ \\
\hline
\end{tabular}


predominantly mulga (A. aneura), and species of Eremophila, Dodonaea and Cassia, leading to reduced ground cover and a subsequent reduction in fire frequency (Passmore and Brown 1992). Fire has been identified as one of the major threats to koalas throughout their range (Lee et al. 1990; Reed and Lunney 1990).

There is substantial evidence that the recruitment of many long-lived perennial tree species by seed or vegetative suckers is inhibited under grazing pressure (Lange and Graham 1983; Auld 1995). It has long been suggested that in Australia the major cause of reduced regeneration of perennial trees and grasses were rabbits, goats (Lange and Graham 1983) and domestic stock (Auld 1995), particularly in riverine communities (Reid and Fleming 1992). However, anecdotal evidence collected throughout this study suggests that Eucalyptus species in riverine communities regenerate well in comparison to some residual communities. Many riverine communities had trees that fitted into a range of size classes, which indicates at least some recruitment. In many residual communities, particularly Habitat Unit 10, little evidence of recruitment of Eucalyptus species was recorded, with most trees being of similar DBH. This suggests that these communities are not stable in the long term, and could decline, as too few recruits are available to replace mature trees that die (sensu Auld 1995).

The apparent suppression of regeneration in these communities could be caused partially by domestic stock, but is likely to be primarily caused by feral goats, which occur in high densities in these areas. Aerial surveys of the semi-arid rangelands of western New South Wales and Queensland indicate a minimum feral goat population of $\sim 1$ million, with the eastern portion of the mulgalands having an estimated mean density of $1.1-2.0$ goats $\mathrm{km}^{-2}$ (Southwell et al. 1993). While they may be reasonably accurate on a regional scale, localised groups of goats within many residual communities far exceed these reported densities (BJS and LP, personal observations). We suggest that the suppression of regeneration in these communities is one of the most serious long-term threats to koala populations, and potentially other taxa of native species (e.g. birds, scansorial lizards), within the mulgalands.

We suggest that it is possible that koala populations in the study area have accrued benefit from other land-management practices such as the provision of artificial water and the control of dingoes (Canis familiaris). However, specific studies would be required to support this argument.

\section{Field validation exercise}

On the basis of validation results obtained in riverine communities, our estimate of koala abundance should be conservative. There are two likely explanations for this slight underestimate. First, pellets were sampled only from beneath eucalypts (see Sullivan et al. 2002) so pellets deposited beneath non-eucalypt tree species were not included in our abundance estimate. While non-eucalypt trees form only a minor part of koala diet in the study area (Sullivan et al. $2003 a$ ), it stands to reason that some faecal pellets would be deposited under such trees. Second, the method for detecting the presence/absence of pellets beneath riverine trees is only $90 \%$ accurate, so it is possible that some trees with pellets were excluded from the dataset. However, the estimates are sufficiently accurate to justify their use in the context of the study where an estimate of koala abundance and relative habitat utilisation is being derived for a $19200-\mathrm{km}^{2}$ biogeographic region, and where no other such estimates have been attempted.

\section{Conclusions}

Koala populations in the mulgalands occur at the western edge of their northern distribution, and may be considered peripheral populations. Peripheral populations can be geographically or ecologically marginal. The former are separated from central populations by distance and the latter experience different abiotic and biotic conditions. However, these two types of peripheral populations are not mutually exclusive (Lesica and Allendorf 1995). Considering the geographical location of koala populations within the mulgalands and the apparent climatic control of the edge of their westerly distribution (Sullivan et al. 2003a, 2003b), it is likely that in the mulgalands koalas are both geographically and ecologically marginal. Genetic data has shown that populations in New South Wales and Queensland consist of multiple management units (sensu Moritz 1994; Houlden et al. 1996, 1999). Considering that koala conservation should aim to maintain the species' current ecological amplitude (Sherwin et al. 2000), the peripheral nature and estimated size of the mulgaland's koala population $(63000 \pm 18000)$ should afford them special consideration in future conservation initiatives.

Prior to our study and that of Witt and Pahl (1995) the widely held view regarding koalas in the study area was that they are largely restricted to riverine communities dominated by river red gum and coolabah. While these communities are undoubtedly critical, our study has highlighted the wide variety of vegetation communities utilised by koalas and has emphasised that conservation strategies within the mulgalands must strive to ameliorate the adverse impacts of habitat clearance and fragmentation and conserve a representative mosaic of vegetation with a high level of connectivity.

\section{Management implications}

In this series of papers we have quantified the number of koalas in the mulglands, defined their geographic range, determined relative habitat preferences, and described their dietary preferences. Regional management of the species can now proceed on a much more informed and coordinated 
basis. On the basis of our findings we highlight the following management implications:

(1) The size of the koala population within the mulgalands suggests that it is important in the overall conservation of the species. The results of this study (which provides the first inland estimate of regional abundance) may be used to help clarify the conservation status of the koala and develop practical conservation initiatives, at a regional, state and national level.

(2) Conservation and land-use management strategies within the mulgalands should strive to protect vegetation associations that are otherwise considered to have low fauna conservation values. The residual communities are particularly important in maintaining viable low-density koala populations. Plains communities may also be important for their low-density populations and/or for their potential to act as a conduit between populations.

(3) The high level of protection for riverine communities should be maintained because they sustain the highest-density populations (and $\sim 45 \%$ of estimated abundance) and act as refugia for koala populations in adverse climatic conditions (sensu Gordon et al. 1988; Munks et al. 1996).

(4) Given the flagship nature of koalas, their future management could be crucial in the development of future land-management (e.g. tree clearing) guidelines to engender an increased conservation ethic within the mulgalands.

(5) As a result of our findings, future research can become much more clearly targeted. Key questions are: do koala populations function as a metapopulation, and if so, do source-sink populations occur? If so, where are they?

(6) As proposed by Sherwin et al. (2000), genetic studies should be conducted to identify the degree of demographic independence of populations within the mulgalands.

(7) Mulgaland koala populations should receive special consideration in koala conservation because of the benefits of maintaining the current ecological amplitude of the species throughout its range (Sherwin et al. 2000).

(8) The abundance, sex ratios and fecundity of a representative selection of populations should be monitored over the long term to develop an understanding of the stability of populations throughout the region.

\section{Acknowledgments}

The project would not have been possible without the assistance of the many field volunteers, and the lanholders who happily provided access to their land. Ros Moye and Bruce Wilson, Environmental Protection Agency (EPA), Toowoomba, spent many hours assisting with the GIS. Thanks to the staff of the EPA, Charleville, for logistical support. We are grateful to Bradd Witt for discussions regarding the project, particularly in its design stage. Estimation of faecal pellet production was carried out by permission of the Queensland Department of Environment and Heritage, Scientific Purposes Permit WO/001559/96/ SAA and University of Queensland Animal Experimentation Ethics Approval number GAT/465/96/AKF/Ph.D. This work was funded by the Australian Koala Foundation.

\section{References}

Andren, H. (1994). Effects of habitat fragmentation on birds and mammals in landscapes with different proportions of suitable habitat: a review. Oikos 71, 355-366.

ANZECC 1998. 'National Koala Conservation Strategy.' (Environment Australia: Canberra.)

Auld, T. D. (1995). The impact of herbivores on regeneration in four trees from arid Australia. Australian Rangeland Journal 17, 213-227.

Barnes, R. (1996). Estimating forest elephant abundance by dung counts. In 'Studying Elephants'. (Ed. K. Kangwana.) pp. 38-48. (African Wildlife Foundation: Nairobi.)

Chou, Y. H. (1997). 'Exploring Spatial Analysis in GIS.' (Onword Press.)

Cork, S. J., and Sanson, G. D. (1990). Digestion and nutrition in the koala: a review. In 'Biology of the Koala'. (Eds A. K. Lee, K. A. Handasyde and G. D. Sanson.) pp. 129-144. (Surrey Beatty: Sydney.)

Cork, S. J., Hume, I. D., and Foley, W. J. (2000). Improving habitat models and their utility in koala conservation. Conservation Biology 14, 660-668. doi:10.1046/J.1523-1739.2000.99389.X

Dunning, J. B., Danielson, B. J., and Pulliam, H. (1992). Ecological processes that affect populations in complex landscapes. Oikos 65, $169-173$.

Efron, B., and Tibshirani, R. (1986). Bootstrap methods for standard errors, confidence limits, and other measure of statistical accuracy. Statistical Science 1, 54-77.

Ellis, W. A. H., Sullivan, B. J., Lisle, A. T., and Carrick, F. N. (1998). The spatial and temporal distribution of koala faecal pellets. Wildlife Research 25, 663-668.

Environmental Systems Research Institute (1996). 'Arcview Spatial Analyst. Advanced Spatial Analysis Using Raster and Vector Data.'

Fahrig, L., and Paloheimo, J. (1988). Determinants of local population size in patchy habitats. Theoretical Population Biology 34, 194-213.

Gordon, G., Brown, A. S., and Pulsford, P. (1988). A koala population crash during heatwave conditions in southwestern Queensland. Australian Journal of Ecology 13, 451-461.

Gordon, G., McGreevy, D. and Lawrie, B. (1990). Koala populations in Queensland: major limiting factors. In 'Biology of the Koala'. (Eds A. K. Lee, K. A. Handasyde and G. D. Sanson.) pp. 85-95. (Surrey Beatty: Sydney.)

Hasegawa, M. (1995). Habitat utilisation by koalas (Phascolarctos cinereus) at Point Halloran, Queensland. M.Sc. Thesis, The University of Queensland, Brisbane.

Hasegawa, M., and Carrick, F. N. (1995). First catch your koala! Use of a trap to capture koalas (Phascolarctos cinereus) for ecological studies. Australian Zoologist 30, 68-70.

Hodgson, M. E. (1992). Sensitivity of spatial interpolation models to parameter variation. In 'Technical Papers of the American Congress on Surveying and Mapping'. pp. 113-122.

Houlden, B. A., England, P. R., Taylor, A. C., Greville, W. D., and Sherwin, W. B. (1996). Low genetic variability of the koala (Phascolarctos cinereus) in south east Australia following a severe population bottleneck. Molecular Ecology 13, 1119-1127. 
Houlden, B. A., Costello, B. H., Sharkey, D., Fowler, E. V., Melzer, A., Ellis, W., Carrick, F., Baverstock, P. R., and Elphinstone, M. S. (1999). Phylogeographic differentiation in the mitochondrial control region in the koala Phascolarctos cinereus (Goldfuss 1817). Molecular Ecology 8, 999-1011. doi:10.1046/J.1365-294X.1999. 00656.X

Johnson, C. N., and Jarman, P. J. (1987). Macropod studies at Wallaby Creek. VI. A validation of the use of dung-pellet counts for measuring absolute densities of populations of macropodids. Australian Wildlife Research 14, 139-145.

Lange, R. T., and Graham, C. R. (1983). Rabbits and the failure of regeneration in Australian arid zone Acacia. Australian Journal of Ecology 8, 377-382.

Latham, J. B., Staines, W., and Gorman, M. L. (1996). The relative densities of red (Cervus elaphus) and roe (Capreolus capreolus) deer and their relationship in Scottish plantation forests. Journal of Zoology 240, 285-299.

Lee, A. K., Handasyde, K. A., and Sanson, G. D. (1990). 'Biology of the Koala.' (Surrey Beatty: Sydney.)

Lesica, P., and Allendorf, F. W. (1995). When are peripheral populations valuable for conservation? Biological Conservation 9, 753-760. doi:10.1046/J.1523-1739.1995.09040753.X

Lunney, D., Matthews, A., Moon, C., and Ferrier, S. (2000). Incorporating habitat mapping into practical koala conservation on private lands. Biological Conservation 14, 669-680. doi:10.1046/ J.1523-1739.2000.99386.X

Maxwell, S., Burbidge, A. A., and Morris, K. (1996). 'The 1996 Action Plan for Australian Marsupials and Monotremes.' (IUCN/SSC Australasian Marsupial and Monotreme Specialist Group, Wildlife Australia.)

Melzer, A., and Lamb, D. (1994). Low density populations of the koala (Phascolartos cinereus) in central Queensland. Proceedings of the Royal Society of Queensland 104, 89-93.

Melzer, A., Carrick, F., Menkhorst, P., Lunney, D., and St John, B. (2000). Overview, critical assessment, and conservation implications of koala distribution and abundance. Conservation Biology 14, 619-628. doi:10.1046/J.1523-1739.2000.99383.X

Moritz, C. (1994). Defining 'evolutionarily significant units' for conservation. Trends in Ecology and Evolution 9, 373-375. doi:10.1016/0169-5347(94)90057-4

Munks, S. A., Corkrey, R., and Foley, W. J. (1996). Characteristics of arboreal marsupial habitat in semi-arid woodlands of northern Queensland. Wildlife Research 23, 185-196.

Neldner, V. J. (1984). Vegetation survey in Queensland: south central Queensland. Queensland Botany Bulletin No. 3. Queensland Department of Primary Industries, Brisbane.

Pahl, L. (1996). Koala and bushland survey of west and central Logan City. In 'Koala Research for Management: Proceedings of the Brisbane Koala Symposium'. (Ed. G. Gordon.) pp. 82-92. (World Koala Research Incorporated: Brisbane.)

Passmore, J. G. I., and Brown, C. G. (1992). Property size and rangeland degradation in the Queensalnd mulga rangelands. Australian Rangeland Journal 14, 9-25.

Patterson, R. (1996). The distribution of koalas in Queensland, 1986-1989. In 'Koala Research for Management. Proceedings of the Brisbane Koala Symposium'. (Ed. G. Gordon.) pp. 75-81. (World Koala Research Incorpoarated: Brisbane.)

Phillips, B. (1990). 'Koalas - The Little Australian We'd All Hate To Lose.' (Australian National Parks and Wildlife Service, Australian Government Publishing Services: Canberra.)

Phillips, S. (2000). Population trends and the koala conservation debate. Conservation Biology 14, 650-659. doi:10.1046/J.1523-1739. 2000.99387.X
Phillips, S., Callaghan, J., and Thompson, V. (2000). The tree species preference of koalas (Phascolarctos cinereus) inhabiting forest and woodland communities on Quaternary deposits in Port Stephens area, New South Wales. Wildlife Research 27, 1-10.

Reed, P., and Lunney, D. (1990). Habitat loss: the key problem for the long-term survival of koalas in New South Wales. In 'Koala Summit: Managing Koalas in New South Wales'. (Eds D. Lunney, C. A. Urquhart and P. Reed.) pp. 9-31. (New South Wales National Parks and Wildlife Service: Sydney.)

Reid, J., and Fleming, M. (1992). The conservation status of birds in arid Australia. Australian Rangeland Journal 14, 65-91.

Sharp, A. (1995). 'The Koala Book.' (David Bateman Ltd: Auckland.)

Sherwin, B., Timms, P., Wilcken, J., and Houlden, B. (2000). Analysis and conservation implications of koala genetics. Conservation Biology 14, 639-649. doi:10.1046/J.1523-1739.2000.99384.X

SLATS (1999a). Land cover change in Queensland 1991-1995. Issued July 1999. Resources Sciences and Knowledge, Queensland Department of Natural Resources, Brisbane.

SLATS (1999b). Land cover change in Queensland 1995-1997. Issued August 1999. Resources Sciences and Knowledge, Queensland Department of Natural Resources, Brisbane.

SLATS (2000). Land cover change in Queensland 1997-1999. Issued September 2000. Resources Sciences and Knowledge, Queensland Department of Natural Resources, Brisbane.

Southwell, C., Weaver, K., Sheppard, N., and Morris, P. (1993). Distribution and relative abundance of feral goats in the rangelands of eastern Australia. Australian Rangeland Journal 15, 331-333.

Sullivan, B. J., Baxter, G. S., and Lisle, A. T. (2002). Low-density koala (Phascolarctos cinereus) populations in the mulgalands of south-west Queensland. I. Faecal pellet sampling protocol. Wildlife Research 29, 455-462. doi:10.1071/WR00110

Sullivan, B. J., Norris, W., and Baxter, G. S. (2003a). Low-density koala (Phascolarctos cinereus) populations in the mulgalands of south-west Queensland. II. Distribution and diet. Wildlife Research 30, 331-338. doi:10.1071/WR00032

Sullivan, B. J., Baxter, G. S., and Lisle, A. T. (2003b). Low-density koala (Phascolarctos cinereus) populations in the mulgalands of south-west Queensland. III. Broad-scale patterns of habitat use. Wildlife Research 30, 583-591. doi:10.1071/WR02036

Thackway, R., and Cresswell, I. D. (1995). An interim biogeographic regionalization for Australia: a framework for setting priorities in the national reserves system cooperative program. Reserves System Unit, Australian Nature Conservation Agency, Canberra.

Walker, B. H., and Steffen, W. L. (1993). Rangelands and global change. Australian Rangeland Journal 15, 95-103.

Watson, D. F., and Philip, G. M. (1985). A refinement of inverse distance weighted interpolation. Geo-Processing 2, 315-327.

Wilson, B. A. (1999). Mulga lands. In 'The Conservation Status of Queensland's Bioregional Ecosystems'. (Eds P. Sattler and R. Williams.) pp. 6-1-6-35. (Environmental Protection Agency: Brisbane.)

With, K. A., Gardner, R. H., and Turner, M. G. (1997). Landscape connectivity and population distributions in heterogeneous environments. Oikos 78, 151-169.

Witt, G. B., and Beeton, R. J. S. (1995). The regional implications of 'naturalness' in protected area management: a case study from the Queensland mulgalands. In 'Ecological Research and Management in the Mulgalands'. (Eds M. Page and T. Beutel.) pp. 177-182. (University of Queensland, Gatton College: Brisbane.)

Witt, G. B, and Pahl, L. I. (1995). Mulgaland communities of south-west Queensland as habitat for koalas. In 'Ecological Research and Management in the Mulgalands'. (Eds M. Page and T. Beutel.) pp. 91-95. (University of Queensland, Gatton College: Brisbane.)

Manuscript received 27 May 2002; accepted 2 October 2003 